\title{
Merleau-Ponty y el esta- linismo: sobre El cero y el infinito de Koestler
}

Juan Manuel Aragüés Estragués

Universidad de Zaragoza, España

(c) 


\section{Merleau-Ponty y el estalinismo: sobre EI cero y el infinito de Koestler ${ }^{\star}$}

Resumen: en la segunda mitad de los años 40, Merleau-Ponty realizó una cerrada defensa del marxismo y, como consecuencia, de la Unión Soviética. Para ello, en su obra Humanismo y terror se aplica a una crítica de la novela de A. Koestler EI cero y el infinito. La tesis fundamental defendida por Merleau-Ponty es el carácter humanista del marxismo.

Palabras clave: marxismo, humanismo, existencialismo, violencia, liberalismo.

\section{Merleau-Ponty and Stalinism: On Koestler's Darkness At Noon}

Abstract: during the second half of the fortys' decade, Merleau-Ponty made a strong defense in terms of marxism and, as a consequence, about the Soviet Union. To archieve it, he includes it in a critique of A. Koestler's novel Darkness at Noon in Humanism and Terror. The essential thesis defended by Merleau-Ponty is the humanist nature of Marxism.

Keywords: marxism, humanism, existencialism, violence, liberalism.

Fecha de recepción: 24 de abril de 2017

Fecha de aceptación: 2 de agosto de 2017

Forma de citar (APA): Aragüés, J. M. (2018). Merleau-Ponty y el estalinismo: sobre El cero y el infinito de Koestler. Revista Filosofía UIS, 17(1), doi: http://dx.doi. org/10.18273/revfil.v17n1-2018008

Forma de citar (Harvard): Aragüés, J. M. (2018). Merleau-Ponty y el estalinismo: sobre El cero y el infinito de Koestler. Revista Filosofía UIS, 17(1), 167-180.

Juan Manuel Aragüés Estragués: español. Doctor en Filosofía. Profesor Titular de la Universidad de Zaragoza, España.

Correo electrónico: aragues@unizar.es

* Artículo de reflexión derivado de investigación. 


\section{Merleau-Ponty y el estalinismo: sobre El cero y el infinito de Koestler'}

\section{Introducción}

Años finales de la década de los 40: los gélidos aires de la Guerra Fría comienzan a recorrer Europa. Los intelectuales cavan sus trincheras. Tras la desolación que la Segunda Guerra Mundial había producido, un nuevo enfrentamiento, más sordo, se tejía sobre las ruinas de las ciudades europeas. Dos bloques antagónicos se configuran en la política mundial, bloques que, en el caso francés muy especialmente, encuentran su correlato en la política interior. Si la Unión Soviética y Estados Unidos se aprestan a una confrontación, ideológica y política, que dominará el panorama mundial durante decenios, la política francesa queda presa del antagonismo entre gaullistas y comunistas. Pocos son los intelectuales capaces de articular, o cuando menos de intentar, una posición específica y discrepante con estas dos cosmovisiones dominantes. En el caso francés, esta intelectualidad es la que se articula en torno a la revista Les Temps Modernes, fundada en 1945 por J. P. Sartre, M. Merleau-Ponty y S. de Beauvoir. La pretensión de articular una "tercera vía" entre gaullistas y comunistas, Estados Unidos y Unión Soviética, queda establecida en el manifiesto fundacional, y no es sino continuación de la política resistente que habían desarrollado Merleau-Ponty y Sartre ya en 1941 con la creación del grupo Socialisme et liberté. Ciertamente, la apuesta por el socialismo, por el marxismo, obstaculiza la equidistancia, y en los escritos de esta época de ambos autores siempre se observa, en última instancia, una defensa de la URSS. Pero desde posiciones de autonomía. No en vano, una de las polémicas más duras de la época será la que enfrente entre 1946 y 1949 a Sartre y Lukács (Aragüés, 2005).

\footnotetext{
${ }^{1}$ El artículo debe ser considerado dentro del contexto del proyecto "Gobierno de sí y políticas de la subjetividad en el contexto de la crisis de la racionalidad neoliberal", concedido por el Ministerio de Economía y Competitividad en 2016 (FFI2016-76856-R), con una duración de dos años y del que soy segundo investigador principal.
} 
Si Sartre confronta agriamente con Lukács y con el PCF, Merleau-Ponty se afanará en la denuncia de las posiciones de la trinchera liberal. De ahí su texto Humanismo y Terror, publicado en 1947, pero en realidad redactado a lo largo de 1946 y publicado por capítulos en Les Temps Modernes. Dicho texto es respuesta a la novela de A. Koestler Darness at noon, traducida al francés (y posteriormente al castellano) como El cero y el infinito. En esta novela, Koestler, antiguo militante comunista, denuncia con vehemencia, en una fecha tan temprana como 1938-40, el estalinismo y el régimen de terror imperante en la Unión Soviética.

\section{El cero y el infinito}

El campo de la literatura, y significativamente de la literatura de origen comunista, es uno de los primeros y más efectivos lugares desde el que se va a proceder a una crítica del estalinismo y del proceso de degeneración de la Revolución. Nosotros, de E. Zamiatin, redactada entre 1919 y 1921, supone el comienzo de esta literatura crítica, que se prolonga con obras como La excavación de Platonov (1929-1930), Caoba de Pilniak (1929), Moscú-frontera de Jiri Weil (1937), El caso Tulayev de V. Serge (1947) o la monumental Vida y destino de V. Grossmann. La deriva autoritaria de la Revolución, en lo que se refiere al campo intelectual, tiene un hito fundacional, que es la condena en Pravda, en 1924, de las obras filosóficas Historia y conciencia de clase de G. Lukács y Marxismo y filosofía de K. Korsch. Tras unos iniciales momentos en los que la Revolución alienta la innovación artística y el cambio en las costumbres, y cuya consecuencia más inmediata es el estallido de numerosos focos de producción cultural de vanguardia, como el que se articula en torno al Levyi Front Iskusstva (LEF) de Pasternak y Maiakovskii, el rumbo del proceso revolucionario se encamina hacia un movimiento de repliegue político que llevará al establecimiento de la defensa del poder establecido como eje del actuar revolucionario. La construcción del socialismo en un solo país, lema con el que Stalin accede al poder, y del que Sartre dice "ese día los ángeles lloraron" (Sartre, 1996, p. 156), va a implicar la defensa en exclusividad de aquellas políticas que favorezcan la consolidación del poder en la URSS y, por lo tanto, a repudiar cualquier manifestación de disidencia, por leve que ésta sea. En el campo político, las consecuencias son inmediatas, con la salida de Trotskii de la URSS y los procesos de Moscú, que se desarrollan a lo largo de los años 30; en el intelectual, la cultura quedará sometida al férreo control de las organizaciones oficiales, que dictarán la línea a seguir en el campo de la literatura, el cine o la música. No es posible, en cualquier caso, separar ambos procesos, pues como le dice, de manera premonitoria, Pilniak a Serge en una carta fechada en 1933, "no hay un solo adulto pensante en este país que no haya creído que podía ser fusilado" (Serge, 2007, p. XVI-XVII). Pilniak desapareció sin dejar rastro en 1937. 
La Revolución había realizado un bucle perverso y se había cerrado sobre sí misma, engullendo, en los procesos de Moscú, a quienes, como Bujarin, la habían alentado. Ya no se trataba sino de defender el poder establecido. Frente a la idea de Revolución como un proceso sin clausura, permanente, se instaura la idea de la revolución ya terminada y clausurada. Este es el contexto en el que se gesta la novela de Koestler. La idea de fondo, también presente en las novelas anteriormente citadas, muy especialmente en las de Serge y Grossman, en las que se denuncia desde posiciones comunistas la traición a la Revolución por parte de Stalin, es que los procesos de Moscú suponen la escenificación del fin de los ideales que habían alentado la Revolución. La inadecuación entre medios y fin, o incluso, el olvido de los fines con los que había nacido la Revolución, la pérdida del "lastre moral", el olvido de los individuos, la violencia, la conversión del Partido en exclusivo criterio de verdad son las principales críticas vertidas por Koestler a lo largo de las páginas de El cero y el infinito, en las que Rubashov, el alter ego de Bujarin, se ve obligado a reconocer su traición al Partido.

Sin embargo, desde nuestro punto de vista, el argumento crítico de mayor peso que utiliza Koestler, y que reproduce algo ya enunciado, en cierto modo, por Zamiatin, es la conversión de la teoría revolucionaria en instrumento de defensa del poder establecido. Es decir, su transformación en dogma, en pensamiento constituido. Escribe Koestler:

\begin{abstract}
Ahora la vieja guardia estaba agotada: la lógica de la Historia quería que cuanto más estable se fuera haciendo el régimen, más rígido fuera, con el fin de impedir que las inmensas fuerzas dinámicas liberadas por la Revolución se volvieran sobre sí mismas y la hicieran añicos. Había terminado el tiempo de los congresos filosóficos; en lugar de los retratos de antaño, una manchita clara brillaba sobre el papel pintado de Ivanov; los principios de una filosofía incendiaria dejaban lugar a un período de completa esterilidad. La teoría revolucionaria se había congelado convirtiéndose en un culto dogmático con catecismo simplificado y fácil de asimilar, con el Número Uno como sumo sacerdote pronunciando la misa. Sus discursos y artículos presentaban también en su estilo el carácter de un catecismo infalible; se subdividían en preguntas y respuestas, con una grosera simplificación de los problemas y los hechos. El Número Uno sin duda aplicaba instintivamente la "ley de madurez relativa de las masas" [...] Los aficionados a la tiranía habían obligado a sus súbditos a obrar por decreto; el Número Uno les había enseñado a pensar por decreto (1992, p. 188)².
\end{abstract}

\footnotetext{
${ }^{2}$ La referencia al Número Uno es utilizada también en una composición crítica de Dmitrii Shostakovich, Raiok antiformalista, una divertida parodia sobre los gustos musicales de Stalin compuesta en 1948, como respuesta a las duras críticas recibidas por compositores soviéticos como Prokofiev, Miaskovskii, Jachaturian y el mismo Shostakovich en 1947 por el supuesto fomalismo de su obra.
} 
No muy alejado de la clausura de la Revolución que ya había denunciado Zamiatin:

-iEs una locura! No tiene ni pies ni cabeza. ¿No ves que estáis preparando una revolución?

-Sí, una revolución. ¿Por qué no tiene ni pies ni cabeza?

-Porque no puede haber revolución. Porque nuestra revolución fue la última y no puede haber otra. Todo el mundo lo sabe...

Vi esbozarse el triángulo irónico y agudo de sus cejas:

-Querido amigo, eres matemático, eres además filósofo matemático; dime cuál es la última cifra.

-¿Cómo? No te entiendo, ¿qué última cifra?

-Pues la de encima, la última, la mayor...

-Pero, I, es absurdo. El número de cifras es indefinido, no puede existir una última cifra.

-Entonces, ¿por qué hablas de última revolución? No hay última revolución, el número de revoluciones es siempre infinito. El último es para los niños: el infinito les asusta y tienen que dormir tranquilamente por la noche (1991, p. 155).

No cabe duda, tras la lectura de estos textos, de que el debate que se produce entre Trotskii y Stalin en torno al carácter de la Revolución ya había sido abordado en la literatura (Zamiatin) y que, incluso, seguía vigente. Bien es cierto que, si Serge o Grosmann lo continúan desde posiciones que se autodefinen como comunistas, Koestler abandona su militancia y pasa a colaborar con la trinchera liberal. Y ahí es donde se encuentra una de las claves de la crítica de Merleau-Ponty.

\section{Humanismo y terror}

El filósofo alemán P. Sloterdijk coloca el fin del humanismo en 1945, con el fin de la Segunda Guerra Mundial (Sloterdijk, 2000). A tenor de los hechos, esa ubicación cronológica resulta chocante, por cuanto, al menos en Francia, el período inmediatamente posterior al final del conflicto bélico ve la proliferación de obras en las que se produce una reivindicación del humanismo. Con la excepción de Heidegger, en su Carta sobre el humanismo, buena parte de la intelectualidad europea realiza una encendida defensa del humanismo. Con Merleau-Ponty, uno de los casos más significativos es el de su colega Sartre, quien pronuncia en 1945 una conferencia que lleva por título un verdadero oxímoron: El existencialismo es un humanismo. Quizá sea la vivencia de los horrores de la guerra lo que empuja a dichos intelectuales a una inocente defensa del humanismo como concepto; defensa del concepto que es negada al mismo tiempo en la práctica teórica de sus obras. Y, sin embargo, defensa del concepto. Acaso porque se pretende evitar que un concepto de prestigio social sea apropiado en exclusividad por la posiciones liberales. 
Es precisamente frente a las críticas liberales, frente a las que Merleau-Ponty va a desarrollar una potente defensa del marxismo. Y esa defensa del marxismo le conduce a una defensa, "en última instancia", de la URSS, pues todavía late en el ambiente la brutal afirmación de Aragon de que "defender a Bujarin es defender a Hitler". En el marco de la terrible polarización del momento, la defensa del que se cree es el instrumento teórico de uno de los bandos en conflicto empuja a Merleau-Ponty a una mayor aproximación a éste. Aunque sea, sin ninguna duda, una aproximación crítica, que no evitará la malquerencia del oficialismo comunista francés, representado por el PCF. Merleau-Ponty es consciente de su complicada situación:

Nos encontramos pues en una situación inextricable. La crítica marxista del capitalismo sigue siendo válida y es evidente que el antisovietismo reúne hoy la brutalidad, el orgullo, el vértigo y la angustia que han encontrado su expresión en el fascismo. Por otro lado, la revolución se ha inmovilizado sobre una posición de repliegue: mantiene y acrecienta el aparato dictatorial al mismo tiempo que renuncia a la libertad revolucionaria del proletariado en sus Soviets y en su Partido y a la apropiación humana del Estado. No se puede ser anticomunista, no se puede ser comunista (1968, pp. 15-16).

La línea de crítica de Merleau-Ponty hacia Koestler radica en la incorrección de sus análisis desde una perspectiva marxista y en la aceptación y defensa de las posiciones liberales. Crítica que va más allá de las tesis de El cero y el infinito y que apunta, más bien, a las actitudes políticas adoptadas por Koestler en los años 40. Comenzando por la última cuestión, la defensa de posiciones liberales, MerleauPonty reprocha a Koestler, en primer lugar, el manejo de categorías burguesas con voluntad de universalidad y atemporalidad, es decir, la naturalización de los conceptos fuera de su empleo histórico y social. En efecto, entiende MerleauPonty, de manera correcta, que uno de los elementos caracterizadores del discurso liberal es la defensa de conceptos tales como libertad, o el rechazo de otros, como el de violencia, de manera descontextualizada, es decir, sin atender a la "situación", por utilizar un vocablo caro al existencialismo, concreta. Así, la libertad no puede ser defendida de un modo genérico, de manera universal y abstracta, sino que debe ser referida a una situación histórica concreta y a una práctica social determinada. Así lo explicita Merleau-Ponty: " [...] el uso y la idea misma de libertad ya no pueden ser en el presente lo que eran antes de Marx. Tenemos derecho a defender los valores de libertad y de conciencia únicamente cuando estamos seguros, al hacerlo, de no servir a los intereses de un imperialismo y de no asociarnos a sus mistificaciones" (1968, p. 17). Merleau teoriza la existencia de dos tipos de libertades: 
[...] existen dos usos y dos ideas de la libertad. Hay una libertad que es la insignia de un clan, y por lo tanto el lema de una propaganda. La historia es lógica al menos en esto: ciertas ideas tienen con cierta política o con ciertos intereses una conveniencia preestablecida, porque unos y otros suponen la misma actitud frente a los hombres. Las libertades democráticas tomadas como único criterio en el juicio que se establece sobre una sociedad, las democracias absueltas de todas las violencias que ejercen aquí y allá porque reconocen el principio de las libertades y las practican al menos en el interior, en una palabra, la libertad convertida paradójicamente en un principio de separación y fariseísmo, todo esto constituye ya una actitud de guerra. Por el contrario, de la libertad en acto que busca comprender a los otros hombres y que nos reúne a todos, nunca podrá obtenerse una propaganda (1968, p. 39).

En el mismo momento en el que en los textos de Sartre, muy especialmente en los Cahiers pour une morale, redactados entre 1947 y 1948, la relación con el otro se convierte en piedra de toque de construcción de una moral y una política (Aragüés, 1995), Merleau-Ponty entiende la libertad como ejercicio de comprensión de la alteridad. Pues mientras el liberalismo no entiende la sociedad más que como un agregado de átomos intercambiables, por iguales, el existencialismo, como el marxismo, parte del hecho de la diferencia subjetiva como pedestal desde el que construir una política. Y esa diferencia es la que lleva al reconocimiento de la existencia de diferentes posiciones individuales, diferentes situaciones y, por tanto, diferentes valoraciones de lo real que, en última instancia, conducen a una realidad en conflicto. Si el liberalismo, desde su concepción de una naturaleza humana uniforme, universal y atemporal, entiende el conflicto, la violencia, como un epifenómeno indeseable, Merleau-Ponty defiende que la violencia forma parte constitutiva de las relaciones humanas y de las sociedades. Desde esa perspectiva, la del análisis de la violencia, Merleau-Ponty entiende que el libro de Koestler aborda, "el problema de nuestro tiempo" (Merleau-Ponty, 1968, p. 46). Y, en efecto, como anticipábamos previamente, los horrores de la reciente guerra sirven de campo abonado al discurso liberal de repudio de la violencia:

La guerra ha gastado tanto los corazones, ha exigido tanta paciencia, tanto valor, prodigó tanto los horrores gloriosos o no gloriosos, que los hombres no tienen siquiera suficiente energía para mirar la violencia a la cara, para verla allí donde se encuentra. Han deseado tanto alejar al fin la presencia de la muerte y volver a la paz, que no pueden tolerar el no encontrarse en ella todavía, y una visión un poco franca de la historia es considerada una apología de la violencia (Merleau-Ponty, 1968, pp. 35-36);

como si ésta fuera fruto de la exclusiva voluntad humana y no hiciera falta más que su denuncia para su superación. Merleau-Ponty en este punto es tajante, al entender que la violencia, de uno u otro modo, acompaña a las relaciones humanas: "La violencia es nuestro mundo en tanto que estamos encarnados" (1968, p. 155); y que sólo la transformación de éstas posibilitará su superación. 
La burguesía enmascara sus violencias, del mismo modo que enmascara su ser de clase revistiéndolo de naturaleza humana. Por todo ello, entiende el autor de Humanismo y terror, defender la libertad abstracta y criticar genéricamente la violencia supone colocarse del lado del imperialismo.

Una segunda línea crítica contra el libro de Koestler es la que hace referencia al desconocimiento del marxismo por parte de éste. Koestler, según Ponty, desconoce, o deforma, la teoría de la historia de Marx, al tiempo que desatiende el papel que el marxismo concede al tema de la subjetividad. Si, como veremos más adelante, la defensa de la URSS por parte de Merleau-Ponty es una defensa tremendamente matizada, sin embargo, por lo que respecta al marxismo, la posición del filósofo francés es de una gran contundencia. Si Sartre esperó hasta 1960, en el marco de su Crítica de la razón dialéctica, para calificar al marxismo como "filosofía insuperable de nuestros tiempos" (2004, p. 10), aunque éste sea también el momento de marcar distancias con el estalinismo, Merleau-Ponty quema etapas y realiza esa reivindicación del marxismo en Humanismo y terror. La argumentación es tajante:

Considerado de cerca, el marxismo no es una hipótesis cualquiera, reemplazable mañana por otra; es el simple enunciado de las condiciones sin las cuales no habría humanidad en el sentido de una relación recíproca entre los hombres, ni racionalidad en la historia. En ese sentido no es una filosofía de la historia, es la filosofía de la historia, y renunciar a ella es trazar una cruz sobre la Razón histórica. Después de lo cual no hay más que ensueños y aventuras (Merleau-Ponty, 1968, p. 200).

En la época en la que, en los mencionados Cahiers pour une morale, Sartre teoriza que la única teoría de la historia que confiere sentido a la misma es la de Hegel, Merleau-Ponty argumenta que "la historia no existe si no constituye el advenimiento de una humanidad y la humanidad el reconocimiento mutuo de los hombres como hombres" (Merleau-Ponty, 1968, p. 204), es decir, si no se lleva a cabo lo que él entiende es el programa marxista, al que no en vano también califica, risum teneatis, de humanismo. De ahí, de esa defensa a ultranza de la teoría de la historia del marxismo, la condena a un Koestler al que se considera desconocedor y deformador de la teoría de Marx:

En el pensamiento de Rubashov y en el comunismo de Koestler, la historia deja de ser lo que era para Marx: la realización visible de los valores humanos por medio de un proceso que comporta giros dialécticos, pero que, por lo menos no puede dar la espalda a sus fines. La historia deja de ser la atmósfera vital del hombre, la respuesta a sus ruegos, el lugar de la fraternidad revolucionaria (Merleau-Ponty, 1968, p. 59). 
Por lo que respecta al tema de la subjetividad, Koestler reproduce el planteo liberal según el cual el marxismo, y su práctica política, el comunismo, se despreocupan totalmente del sujeto, para atender en exclusiva a estructuras colectivas. En su dimensión política, el individuo, piedra de toque del discurso liberal, aunque en una versión abstracta y naturalizada que, también, lo disuelve en la generalización, queda sometido a la colectividad y menospreciado frente a la misma; en su versión teórica, cualquier reflexión en torno a la subjetividad desaparece. Merleau-Ponty protesta ante la argumentación de Koestler, pues entiende que, a diferencia del liberalismo, sólo el marxismo teoriza una subjetividad concreta, en situación, imbuida en la sociedad y la historia:

En este caso -argumenta Merleau refiriéndose al tema de la subjetividadcomo en muchos otros, Koestler plantea la cuestión en términos premarxistas. El marxismo no es la negación de la subjetividad y de la actividad humana, ni el materialismo cientificista del cual partió Rubashov; es, más bien, una teoría de la subjetividad concreta y de la actividad concreta, es decir, comprometidas en una situación histórica. Rubashov cree descubrir una contradicción moral en el corazón del pensamiento comunista, entre la fatalidad y la revolución: "El individuo -dice--, engranaje de un reloj con cuerda hasta la eternidad y que nada podía detener o influir, estaba colocado bajo el signo de la fatalidad económica, y el Partido exigía que el engranaje se revelase contra el reloj y cambiara su movimiento". ¿Pero quién afirma que la historia es un reloj y el individuo un engranaje? No es Marx, es Koestler (Merleau-Ponty, 1968, pp. 65-66).

Si bien es cierto que en Marx es posible encontrar las bases para una teoría materialista de la subjetividad, si también lo es que diferentes autores habían apuntado en esa dirección, como es el caso de Lukács o Korsch, también lo es que el oficialismo marxista estaba construyendo una versión dogmática y mecanicista del mismo en el que la subjetividad, por decirlo con palabras del Sartre de la Crítica de la razón dialéctica, "queda disuelta en un baño de ácido sulfúrico". Ahora es Merleau quien, en su encendida defensa del marxismo, lo convierte en una abstracción y no atiende al momento histórico de su desarrollo, a las deformaciones que en la teorización marxista está produciendo el estalinismo.

Crítica de las posiciones liberales, defensa del marxismo. Esta es la actitud teórica de Merleau-Ponty frente al texto de Koestler. Ahora bien, ello no quiere decir que el autor de Humanismo y terror se ubique en la trinchera soviética. Su pretensión política es muy otra: la construcción de una tercera vía entre comunismo y liberalismo, pues "la política de hoy en día es, verdaderamente, el dominio de las cuestiones mal planteadas, o planteadas de tal manera que no se puede estar con ninguna de las dos fuerzas en presencia" (Merleau-Ponty, 1968, p. 23). Y a diferencia de Sartre, quien entiende que para realizar una tal política es precisa también una tercera vía filosófica entre materialismo e idealismo, tal como teoriza en una obra de 1946, Materialismo y revolución, base de su polémica con 
Lukács, Merleau pretende desarrollar dicha política desde posiciones marxistas. Como ya hemos dicho, la creación de Les Temps Modernes es uno de los pasos en esta política de tercera vía.

\begin{abstract}
Nuestro papel tal vez no es muy importante, pero es preciso mantenerse en él. Eficaz o no, consiste en aclarar la situación ideológica, en subrayar, más allá de las paradojas y de las contingencias de la historia presente, los verdaderos términos del problema humano, recordar a los marxistas su inspiración humanista, recordar a las democracias su hipocresía fundamental y mantener intactas, contra las propagandas, las posibilidades que tiene todavía la historia de tornarse clara (Merleau-Ponty, 1968, p. 228).
\end{abstract}

Ahora bien, tercera vía no significa, para Merleau-Ponty, equidistancia, pues del texto puede desprenderse, en última instancia, una justificación de la actitud soviética y, por lo tanto, de los juicios de Moscú. Justificación tanto en el plano práctico como en el teórico. En el plano práctico, en primer lugar, el asedio a que se había visto sometida la URSS desde el inicio mismo de la revolución justifica la respuesta a las actitudes de oposición interna:

Es cierto -escribe Merleau-Ponty-, no hubo entre Hitler y Bujarin ninguna entrevista de Montoire; cuando Bujarin fue juzgado, el enemigo no estaba ya o no estaba todavía sobre el territorio de la URSS. Pero en un país que no conoció, casi desde 1917, sino situaciones-límites, aun antes de la guerra y antes de la invasión, la oposición podía aparecer como traición (MerleauPonty, 1968, p. 88);

en segundo lugar, acusar a la URSS de violencia desde el campo liberal es la expresión de un doble rasero histórico intolerable y, como se ha dicho más arriba, un olvido interesado del carácter inherente de la violencia a las sociedades humanas: "Pero todas las revoluciones reunidas no han derramado más sangre que las que derramaron los imperios. No hay más que violencias, y la violencia revolucionaria debe ser preferida porque tiene un porvenir de humanismo" (Merleau-Ponty, 1968, p. 153). Humanismo, nuevamente el humanismo. La reivindicación del mismo es una constante en el texto de Merleau-Ponty. Y el humanismo se convierte en fundamento para la defensa teórica de la URSS, en la medida en que la revolución es el instrumento para la construcción de un nuevo humanismo de base proletaria. Merleau-Ponty toma como base para sus argumentaciones textos de Marx que habían salido a la luz a finales de los años 20, principios de los 30, en concreto La ideología alemana y Manuscritos de economía y filosofía. 
La condición del proletariado -escribe Merleau-Ponty- es tal que se separa de las particularidades no por el pensamiento y por un proceso de abstracción, sino en la realidad y por el movimiento mismo de su vida. Sólo él es la universalidad que piensa, sólo él realiza la conciencia de sí cuyo esbozo han trazado, en la reflexión, los filósofos. Con el proletariado la historia sobrepasa las particularidades del provincianismo y del chauvinismo [...] es universal de hecho, visiblemente y en su misma vida (Merleau-Ponty, 1968, p 162).

La revolución, por lo tanto, debe apuntar al futuro, no regirse por las normas del pasado. La legalidad burguesa, anclada en el pasado, en el poder constituido del viejo régimen, no puede servir de vara de medida del proceso conducente a un nuevo orden. La revolución no puede estar condicionada por una legalidad y una moralidad que le son ajenas. No sólo ajenas, sino hostiles.

Ser revolucionario -argumenta Merleau-Ponty- es juzgar lo que existe
en nombre de lo que todavía no existe, tomándolo como más real que lo
real. El acto revolucionario se presenta a la vez como creador de la historia
y como verdadero respecto del sentido total de esta historia, y le es esencial
admitir que ninguno está dispensado de ignorar esta verdad que comprueba
y realiza indivisiblemente, como los tribunales burgueses postulan que nadie
está dispensado de conocer la ley establecida. La justicia burguesa toma
al pasado como última instancia, la justicia revolucionaria al porvenir. Esta
juzga en nombre de esa verdad que la Revolución está tornando verdadera;
sus debates forman parte de la praxis, que puede estar muy bien motivada,
pero que sobrepasa todos sus motivos. Es por eso que [sic] no se ocupa de
saber cuáles han sido los móviles o las intenciones, noble o innobles, de los
acusados: se trata de saber si de hecho su conducta, expuesta sobre el plano
de la praxis colectiva, es revolucionaria o no (Merleau-Ponty, 1968, pp. 71-72).

Ello le lleva a una contundente, y peligrosa, conclusión: "Los procesos de Moscú son comprensible sólo entre los revolucionarios, es decir, entre hombres convencidos de hacer la historia y que por consiguiente ven ya el presente como pasado, y como traidores a los que dudan" (Merleau-Ponty, 1968, p. 73).

\section{Conclusión}

En el difícil ejercicio de equilibrio que Merleau-Ponty ha intentado realizar a lo largo de Humanismo y terror, la pretensión más evidente del autor es la de salvar la teoría aunque la práctica pudiera ser condenada, defender el marxismo aunque hubiera que conceder la degeneración de la URSS: "La decadencia del humanismo proletario no es una experiencia crucial que anula todo el marxismo" (MerleauPonty, 1968, p. 201), escribe con contundencia. Pues, a pesar de que todo el texto se ve surcado por una soterrada defensa de la URSS, también existe un constante reconocimiento de la posible degeneración del proceso revolucionario. MerleauPonty constata la existencia de una "regresión de la ideología proletaria" (187) en la 
Unión Soviética, lo que le lleva a preguntarse si "en lugar de una sociedad humana y abierta a los proletarios de todos los países no veremos aparecer un nuevo tipo de sociedad, que falta estudiar, pero a la cual no es posible reconocer el valor ejemplar de lo que Marx llamaba "la sociedad sin clases" (188). Pero de lo que no cabe duda, lo hemos referido más arriba, es de la justeza, para Merleau-Ponty, de los planteamientos marxistas. Puede incluso resultar sorprendente que el mismo autor que unos años más adelante criticará el "ultrabolchevismo de Sartre", defienda en estos momentos posiciones teóricas mucho más cercanas al marxismo de lo que hacía en los finales años 40 el autor de El ser y la nada.

El juicio político sobre la URSS queda en suspenso, no es posible condenarla, pues ello supondría hacer el juego al liberalismo; no es posible identificarse con ella, a riesgo de convertirse en cómplice de las ya apreciables desviaciones del discurso proletario. Pero, frente a la radicalidad de la denuncia de Koestler, Merleau-Ponty opta por una contextualizada defensa de la actuación soviética en los juicios de Moscú. Colocando la venda antes que la herida, Merleau-Ponty, en todo caso, reconoce: "Dado que el autor de estas líneas no tiene ante sí la historia terminada y está obligado a una perspectiva particular — la de un intelectual francés de 1946su apreciación puede ser recusada" (Merleau-Ponty, 1968, p. 189).

Transcurridos más de 60 años del texto de Merleau-Ponty, ya es posible una "apreciación" situada, tanto del texto de Merleau-Ponty como de la naturaleza de los procesos de Moscú en particular y del estalinismo en general, así como del texto de Koestler. Y lo haremos partiendo de una pregunta que el propio MerleauPonty plantea en el texto. Merleau-Ponty se pregunta lo siguiente al polemizar con las acusaciones de Koestler: "¿Para seguir siendo fiel al sentimiento inmediato de humanidad tal vez hubiera sido necesario renunciar a construir un nuevo Estado?" (Merleau-Ponty, 1968, p. 55). Como bien había expresado a lo largo de su obra, el juicio de un revolucionario se remite al futuro, no al pasado. Y, en efecto, nosotros tenemos la posibilidad de observar aquello que para Merleau-Ponty era su futuro como nuestro pasado. Y a la luz de esa mirada, la pregunta del pensador francés se revela como incorrecta, en la medida en que en la URSS no se construye "un nuevo Estado", con lo que la posible justificación de los hechos remitiendo a los resultados futuros del proceso pierde toda su legitimidad. Merleau-Ponty, desde una perspectiva que se quiere marxista, evita la crítica del estalinismo; Koestler, apartado ya del movimiento comunista, desarrolla una crítica radical. Y, aunque pueda resultar paradójico, desde esa misma óptica marxista que pretende defender Merleau-Ponty, para nuestra práctica política contemporánea resulta más adecuado el libro de Koestler que el de Merleau-Ponty. Pues una política revolucionaria contemporánea debe asentarse en una relectura crítica de aquello que se ha dicho realizar en nombre del marxismo. Y desde esa perspectiva, la denuncia del estalinismo es condición indispensable para cualquier proyecto político que se quiere revolucionario. 
Como bien ha analizado Toni Negri en numerosos textos, la dinámica de la historia es la del conflicto entre el poder constituido y el poder constituyente, entre quienes se hallan instalados en el poder y quienes pretenden una transformación de las relaciones sociales. Sin embargo, en esa dinámica, el poder constituyente en numerosas ocasiones se convierte a su vez, en poder constituido. Dicho en otras palabras, la revolución se clausura, pierde su impulso transformador y degenera, atenta exclusivamente al mantenimiento del poder. Es la dinámica grupal que magistralmente describió J. P. Sartre en su Crítica de la razón dialéctica, en la que los grupos revolucionarios se institucionalizan y pierden de vista los objetivos de la revolución. Sartre lo analizó para la propia revolución rusa. El estalinismo supone un ejemplo más de la clausura de un proceso revolucionario y del triunfo de la reacción.

\section{Referencias}

Aragüés, J. M. (1995). El viaje del Argos. Derivas en los escritos póstumos de J.P. Sartre. Zaragoza: Mira Editores.

Aragüés, J. M. (2005). Sartre en la encrucijada. Madrid: Biblioteca Nueva.

Koestler, A. (1992). El cero y el infinito. Barcelona: Círculo de Lectores.

Merleau-Ponty, M. (1968). Humanismo y Terror. Buenos Aires: La Pléyade.

Sartre, J. P. (1996). Problemas de marxismo. Buenos Aires: Losada.

Sartre, J. P. (2004). Crítica de la razón dialéctica I. Buenos Aires: Losada.

Serge, V. (2007). El caso Tulayev. Madrid: Alfaguara.

Sloterdijk, P. (2000). Normas para el parque humano. Madrid: Siruela.

Zamiatin, E. (1991). Nosotros. Barcelona: Tusquets. 